\title{
PEMANFAATAN MADING BERMUATAN BARCODE EBOOK UNTUK MENINGKATKAN MINAT DAN BUDAYA BACA KELOMPOK PUSAT INFORMASI KONSELING REMAJA (PIK-R)
}

\section{UTILIZATION OF EBOOK BARCODE MADING TO INCREASE INTEREST AND CULTURE READ THE CENTER FOR ADVENTURE COUNSELING INFORMATION CENTER GROUP (PIK-R)}

\author{
Sirojul Munir*, Asep Hidayatullah \\ Universitas Galuh \\ *Email: sirojulmunir518@gmail.com \\ (Diterima 29-01-2021; Disetujui 22-02-2021)
}

\begin{abstract}
ABSTRAK
Minat dan budaya baca masyarakat Indonesia masih sangat rendah terutama di kalangan masyarakat usia remaja. Padahal seiring perkembangan teknologi yang semakin maju justru akan menjadi peluang bagi masyarakat khususnya remaja dalam meningkatkan minat bacanya melalui literasi digital. Laporan pengabdian ini berjudul "Pemanfaatan Mading Bermuatan Barcode Ebook untuk Meningkatkan Minat dan Budaya Baca Kelompok Pusat Informasi Konseling Remaja (PIK-R)”. Pengabdian ini bertujuan untuk memberikan pelayanan kepada masyarakat melalui mading bermuatan barcode ebook untuk meningkatkan minat dan budaya baca remaja dalam kelompok PIK-R.Kegiatan pengabdian ini akan dilaksanakan di PIKR Kecamatan Ciamis. Kegiatan PkM ini terdiri atas empat kegiatan inti, yaitu memilih dan menentukan ebook, membuat link ebook, membuat barcode ebook, dan mensosialisasikan mading bermuatan barcode ebook kepada kelompok PIK-R. Madding bermuatan barcode ebook dalam pengabdian ini terdiri atas 24 barcode ebook: 8 barcode tentang novel, 8 barcode tentang materi PIK Remaja dan 8 barcode tentang isu remaja yang popular. Hasilnya, peserta PIK-R telah menyelesaikan rata-rata 14 bacaan yang dimuat dalam barcode ebook yang tersedia di madding.
\end{abstract}

Kata Kunci: mading, barcode ebook, minat dan budaya baca

\section{ABSTRACT}

The reading culture and interest of Indonesian society are still very low, especially among the teenagers. In fact, as the development of technology is increasingly advanced, it will become an opportunity for people, especially teenagers, to increase their reading interest through digital literacy. This dedication report is entitled "The Use of Ebook Barcodes to Increase Reading Interest and Culture for the Youth Counseling Information Center Group (PIK-R)". This service aims to provide services to the community through wall magazine containing ebook barcodes to increase youth interest and reading culture in the PIK-R group. This service activity will be carried out at PIKR Ciamis District. This PkM activity consists of four core activities, namely selecting and determining the ebook, creating ebook links, making ebook barcodes, and disseminating newsletters containing ebook barcodes to the PIK-R group. Madding contains ebook barcodes in this service consisting of 24 ebook barcodes: 8 barcodes about novels, 8 barcodes about PIK Remaja material and 8 barcodes about popular teen issues. As a result, the PIK-R participants completed an average of 14 readings contained in the barcode ebook available on Madding.

Keywords: wall magazine, ebook barcode, interest and reading culture

\section{PENDAHULUAN}

Membaca merupakan suatu kegiatan atau proses kognitif yang berupaya untuk menemukan berbagai informasi yang terdapat dalam tulisan. Melalui kegiatan membaca seseorang dapat meningkatkan pengetahuan dan wawasan, mengetahui bagaimana keadaan di sekitarnya, keadaan ekonomi global, potensi bisnis, dll. Oleh karena itu, membaca sangat penting bagi setiap orang. Namun, minat baca di Indonesia masih sangat rendah. 
Pemanfaatan Mading Bermuatan Barcode Ebook Untuk Meningkatkan Minat Dan Budaya Baca Kelompok Pusat Informasi Konseling Remaja (PIK-R)

Sirojul Munir, Asep Hidayatullah

Hasil survei UNESCO menunjukkan bahwa minat baca masyarakat yang paling rendah di ASEAN adalah Indonesia. Rendahnya minat baca ini dibuktikan dengan indeks membaca masyarakat Indonesia yang baru $0,001 \%$, artinya dari seribu penduduk, hanya ada satu orang yang masih memiliki minat baca tinggi. Angka ini masih sangat jauh jika dibandingkan dengan angka minat baca di negara lain, misalnya di Singapura yang memiliki indeks membaca sampai 0,45\%. Selain itu, berdasarkan studi Most Littered Nation In the World yang dilakukan oleh Central Connecticut State Univesity pada Maret 2016 lalu, minat baca di Indonesia menduduki peringkat 60 dari 61 negara. Minimnya budaya membaca bangsa Indonesia adalah persoalan yang sangat krusial karena peran budaya baca dalam memperteguh dan mengembangkan peradaban bangsa sangat besar.

Pada zaman dengan perkembangan teknologi yang pesat saat ini, setiap orang dapat memenuhi kebutuhannya akan informasi baru dengan lebih mudah. Hal tersebut dapat diwujudkan dengan hadirnya internet di tengah-tengah masyarakat saat ini. Internet memungkinkan seseorang untuk mengakses informasi dari manapun dan dimana saja tanpa adanya batasan jarak. Tidak hanya itu, dalam penggunaan internet seseorang dapat membagikan atau menerima sekaligus berdiskusi dengan banyak orang mengenai suatu informasi melalui media sosial.

Krisis budaya membaca yang dialami bangsa Indonesia saat ini sudah mulai memperoleh perhatian. Salah satu upaya pemerintah untuk meningkatkan kualitas layanan dan hasil pendidikan keaksaraan sesuai dengan era teknologi saat ini adalah melalui literasi digital. Program ini sebagai upaya menciptakan budaya baca masyarakat terutama remaja dalam menambah wawasannya.

Sesuai dengan Instruksi Presiden Nomor 5 Tahun 2006 tentang Gerakan Nasional Percepatan Penuntasan Wajib Belajar Pendidikan Dasar Sembilan Tahun dan Pemberantasan Buta Aksara (GNP-PWB/PBA) yang telah ditindaklanjuti dengan Peraturan Menteri Pendidikan Nasional Nomor 35 Tahun 2006 tentang Pedoman Pelaksanaan GNPPWB/PBA dan Prakarsa Keaksaraan untuk Pemberdayaan (LIFE) UNESCO-UNLD, Kementerian Pendidikan dan Kebudayaan melalui Direktorat Pembinaan Pendidikan Masyarakat Direktorat Jenderal Pendidikan Anak Usia Dini, Nonformal, dan Informal menyediakan layanan program pendidikan keaksaraan baik keaksaraan dasar yang merupakan program pemberantasan buta aksara maupun keaksaraan usaha mandiri atau menu ragam keaksaraan lainnya yang merupakan program pemeliharan dan peningkatan kemampuan keaksaraan. Hal ini dilakukan karena terdapat kecenderungan para aksarawan 
baru atau penduduk dewasa berkeaksaraan rendah lainnya kembali buta aksara apabila kemampuan keaksaraannya tidak dipergunakan secara fungsional dan berkelanjutan.

Atas dasar itu pada tahun 2013 Direktorat Pembinaan Pendidikan Masyarakat menyediakan layanan pendidikan masyarakat antara lain: Pendidikan Keaksaraan, Pendidikan Kecakapan Hidup dan Kewirausahaan, Pengembangan Budaya Baca Masyarakat, Pengarus utamaan Gender dan Pendidikan Perempuan, Pendidikan Keorangtuaan, dan Penataan Kelembagaan Pendidikan Nonformal.

Berdasarkan uraian di atas, dilakukan kegiatan pengabdian di salah satu organisasi remaja yaitu di Pusat Informasi Konseling Remaja (PIKR). PIKR adalah suatu wadah kegiatan program generasi berencana yang dikelola dari, oleh, dan untuk remaja guna memberikan pelayanan informasi dan konseling tentang perencanaan kehidupan berkeluarga bagi remaja serta kegiatan-kegiatan penunjang lainnya. Pengabdian ini bertujuan untuk memberikan pendidikan dan pelayanan kepada masyarakat berupa madding bermuatan barcode ebook untuk meningkatkan minat dan budaya baca kelompok PIK-R di Kecamatan Ciamis.

\section{BAHAN DAN METODE}

Pengabdian ini berjudul Pemanfaatan Mading Bermuatan Barcode Ebook untuk Meningkatkan Minat dan Budaya Baca Kelompok Pusat Informasi Konseling Remaja $(P I K-R)$. Di era digitalisasi, remaja memerlukan bahan bacaan yang bersifat digital. Salah satu alternatifnya adalah ebook. Kegiatan ini memfasilitasi bahan bacaan digital terpilih melalui barcode yang berisikan beberapa ebook. Dengan adanya bahan bacaan terpilih yang bersifat digital, diharapkan minat dan budaya baca anggota remaja PIKR Tanjungmanggu Oke dapat meningkat.

Pengabdian yang dilaksanakan berfokus pada PIKR Tanjungmanggu OKE (Jl. Tanjungmanggu Rt 001 Rw 009 Kelurahan Sindangrasa, Kecamatan Ciamis, Kabupaten Ciamis) yang beranggotakan 35 orang dengan usia rata-rata 15 tahun.

PkM ini dilaksanakan selama 4 bulan. Bentuk kegiatan yang dilaksanakan adalah pendidikan dan pelayanan pada masyarakat berupa pemanfaatan mading bermuatan barcode ebook untuk meningkatkan minat dan budaya baca kelompok Pusat Informasi Konseling Remaja (PIK-R).

Mekanisme pelaksanaan kegiatan PkM Pemanfaatan Mading Bermuatan Barcode Ebook untuk Meningkatkan Minat dan Budaya Baca Kelompok Pusat Informasi Konseling Remaja (PIK-R) meliputi tahapan-tahapan berikut: memilih dan menentukan ebook, 
Pemanfaatan Mading Bermuatan Barcode Ebook Untuk Meningkatkan Minat Dan Budaya Baca Kelompok Pusat Informasi Konseling Remaja (PIK-R)

Sirojul Munir, Asep Hidayatullah

membuat link ebook, membuat barcode ebook, mensosialisasikan mading bermuatan barcode ebook kepada kelompok PIKR.

\section{HASIL DAN PEMBAHASAN}

Nursisto (2005) mengemukakan bahwa majalah dinding (mading) adalah satu jenis media komunikasi massa tulis yang paling sederhana. Disebut majalah dinding karena prinsip dasar majalah terasa dominan di dalamnya, sementara itu penyajiannya biasanya dipampang pada dinding atau sejenisnya. Prinsip majalah tercermin lewat penyajiannya, baik yang berwujud tulisan, gambar, atau kombinasi dari keduanya. Menurut Suwarno (2011), e-book adalah versi elektronik dari buku. Jika buku pada umumnya terdiri dari kumpulan kertas yang berisi teks atau gambar, e-book berisi informasi digital yang juga dapat berwujud teks atau gambar. Sedangkan menurut Putut Laxman Pendit e-book adalah bentuk buku elektronik secara sederhana bisa dilihat dalam bentuk teks yang tersaji dalam bentuk dokumen yang dibuat dengan wordprocessor, HTML, atau XML. Dengan demikian, mading bermuatan ebook adalah media komunikasi massa yang dipampang pada dinding yang berisikan buku elektronik.

Membaca adalah suatu proses yang dilakukan serta digunakan oleh pembaca untuk memperoleh pesan yang disampaikan penulis melalui media bahasa tulis (Tarigan, 2008). Dalam hal ini, membaca adalah suatu usaha untuk menelusuri makna yang ada dalam tulisan. Senada dengan Tarigan, Dalman (2013) mengemukakan bahwa membaca merupakan suatu kegiatan atau proses kognitif yang berupaya untuk menemukan berbagai informasi yang terdapat dalam tulisan. Dengan demikian, dapat disimpulkan bahwa membaca merupakan proses yang melibatkan kemampuan visual dan kemampuan kognitif untuk mengartikan lambang-lambang huruf agar dapat dipahami dan menjadi bermakna bagi pembaca.

Minat baca merupakan dorongan untuk memahami kata demi kata dan isi yang terkandung dalam teks bacaan tersebut, sehingga pembaca dapat memahami hal-hal yang dituangkan dalam bacaan itu (Dalman, 2013). Orang yang mempunyai minat baca yang kuat akan diwujudkannya dalam kesediaannya untuk mendapat bahan dan kemudian membacanya atas kesadaran sendiri.

Berdasarkan analisis situasi, kelompok PIK-Remaja Tanjungmanggu OKE Kelurahan Sindangrasa Kecamatan Ciamis Kabupaten Ciamis memiliki minat baca yang sangat rendah karena tidak tersedianya bahan bacaan yang beragam dan menarik untuk dibaca. Para remaja menginginkan adanya sebuah inovasi terbaru untuk menarik minat 
baca remaja yang disesuaikan dengan situasi generasi milenial sekarang yang lebih bersahabat dengan teknologi, dengan hal seperti itu mampu meningkatkan minat baca remaja sedikit demi sedikit. Oleh karena itu, diadakan sosialisasi terkait penggunaan barcode ebook sebagai inovasi untuk peningkatan minat baca bagi remaja dan pendampingan pengoptimalisasian minat baca melalui sebuah inovasi madding bemuatan barcode ebook .

Kegiatan pengabdian ini telah dilaksanakan selama 4 bulan, yaitu pada bulan AprilJuli 2020, bertempat di sekertariat PIK-Remaja Tanjungmanggu OKE dan diikuti oleh 20 orang remaja yang tergabung dalam PIK-R di Tanjungmanggu.

Terdapat dua pendekatan yang digunakan dalam pelaksanaan pengabdian tersebut, yaitu pendekatan penyuluhan dan pendampingan. Pada kegiatan pertama, para remaja mendapatkan penyuluhan mengenai penggunaan barcode ebook. Pada pelaksanaan penyuluhan, nampak sekali bahwa peserta penyuluhan yang terdiri atas 20 orang remaja sangat antusias dalam mengikuti penyuluhan tersebut.

Sepekan kemudian setelah diselenggarakannya sosialisasi tentang penggunaan barcode ebook, tampak remaja yang tergabung dalam PIK-Remaja sudah mulai aktif mencoba mengaplikasikan penggunaan barcode ebook yang dipajang di madding sekertariat PIK-Remaja. Adapun sebagai pengenalan awal, tim pengabdi menyiapkan beberapa macam bacaan yang berbentuk barcode ebook diantaranya 8 barcode tentang novel, 8 barcode tentang materi PIK Remaja dan 8 barcode tentang isu remaja yang populer. Melihat situasi dan kondisi remaja di kelompok PIK-Remaja Tanjungmanggu Oke ini yang tadinya hanya memanfaatkan gawaynya untuk bersosial media saja kini berkat kerjasama tim pengabdi, akhirnya gawai yang dimiliki remaja di PIK R Tanjungmanggu Oke dapat bermanfaat juga sebagai media literasi digital mulai dari bacaan untuk hiburan sampai bacaan informasi.

Persoalan menumbuhkan dan meningkatkan semangat baca serta menjadikan membaca sebagai budaya masyarakat Indonesia, merupakan salah satu persoalan yang sangat menarik untuk dibicarakan. Hal ini disebabkan penumbuhan semangat baca mampu membawa pada titik keidealan suatu bangsa. Bangsa yang ideal merupakan cita-cita luhur suatu bangsa karena bangsa yang ideal merupakan ciri dari bangsa yang maju dan beradab sehingga diperlukan cara yang tepat untuk membawa pada kondisi ideal. Salah satu kunci dasar tersebut, yaitu dengan membaca, karena seseorang yang gemar membaca, pasti memiliki gagasan, dan jika memiliki gagasan, diikuti usaha membangun gagasan tersebut menjadi kenyataan. 
Pemanfaatan Mading Bermuatan Barcode Ebook Untuk Meningkatkan Minat Dan Budaya Baca Kelompok Pusat Informasi Konseling Remaja (PIK-R)

Sirojul Munir, Asep Hidayatullah

Dalam era pembangunan serta kemajuan ilmu pengetahuan dan teknologi saat ini, peran perpustakaan dan pusat informasi makin dirasakan kegunaannya oleh masyarakat sebagai sumber informasi pembangunan maupun sarana belajar dan mengajar untuk meningkatkan kecerdasan dan keterampilan. Selain itu, perpustakaan berperan sebagai lembaga pendidikan nonformal yang dapat memberi kesempatan kelangsungan pendidikan sepanjang hayat.

Teknologi sebagai salah satu perangkat komunikasi massa merupakan suatu hal yang sangat penting dalam memacu minat baca masyarakat. Membaca merupakan suatu kegiatan paling dasar dalam pendidikan dan merupakan salah satu keterampilan serta kebiasaan yang paling penting dalam kehidupan sehari-hari. Melalui membaca, masyarakat dapat menemukan ide-ide baru untuk mendapatkan informasi, menambah ilmu pengetahuan dan wawasannya menjadi luas.

Sudarsana (2018) mengatkan bahwa masalah utama kita justru pada mereka yang sudah bisa membaca, tetapi tidak mau membaca. Dalam ilmu informasi, ketidakmauan untuk membaca disebut aliterasi. Masalah ini terjadi karena tidak adanya pendorong atau penggerak untuk membaca serta lingkungan yang memang tidak membaca pada saat orang sudah bisa membaca.

Untuk mencari akar-akarnya tidaklah sulit, karena sering didiskusikan antara lain, masih kuatnya budaya dengar dan budaya lisan, kondisi sosial ekonomi masyarakat belum menunjang minat baca dan daya beli masyarakat, kemajuan teknologi dan komunikasi terutama media elektronik dapat menjadi ancaman untuk minat baca, serta sistem belajar/mengajar dan kurikulum di sekolah atau perguruan tinggi kurang menunjang kegemaran membaca dan menulis.

Senada dengan permasalahan yang ada pada remaja di kelompok PIK-R Tanjungmanggu Oke yang terletak di Kelurahan Sindangrasa, Kecamatan Ciamis ini, akar permasalahan dari rendahnya minat baca pada remaja diantaranya: kurang ditanamkannya minat baca sejak kecil, kesibukan bermain, adanya stigma remaja jika membaca itu tidak penting, tidak tersedianya bahan bacaan yang menarik, sudah memiliki kecanduan terhadap gawai.

Permasalahan di atas tentunya harus dicari upaya untuk meningkatkan minat baca masyarakat khususnya remaja di Tanjungmanggu. Oleh karena itu, tim pengabdi menyediakan konten bacaan yang menarik dan fasilitas perpustakaan yang cukup yaitu dengan memajang beberapa buah barcode ebook di setiap madding yang tersedia di lingkungan sekertariat PIK Remaja. Madding bermuatan barcode ebook ini terdiri atas 24 
barcode ebook: 8 barcode tentang novel, 8 barcode tentang materi PIK Remaja dan 8 barcode tentang isu remaja yang popular.

Hasil yang didapatkan dalam pengabdian ini senada dengan hasil penelitian yang dilakukan oleh Kasiyun (2015), bahwa salah satu cara untuk menumbuhkan minat baca adalah dengan pemilihan kategori bahan bacaan yang ringan dan menarik. Dalam pengabdian ini pun sengaja dipilih bahan bacaan yang ringan dan menarik seperti novel dan isu remaja popoler.

Upaya tersebut terbukti pada akhir pekan bulan Juli 2020 beberapa remaja telah menyelesaikan rata-rata 14 bacaan yang dimuat dalam barcode ebook yang tersedia di madding. Selain itu, kegiatan tersebut mendapatkan respon yang baik dari pengelola dan Pembina PIK Remaja Tanjungmanggu Oke karena kegiatan tersebut sebelumnya tidak pernah ada di lingkungan Tanjungmanggu.

\section{KESIMPULAN DAN SARAN}

\section{Kesimpulan}

Tingginya minat baca sangat dibutuhkan oleh setiap orang, terutama bagi kalangan remaja. Oleh karena itu dibutuhkan berbagai cara untuk meningkatkan minat baca di kalangan remaja ini salah satunya melalui optimalisasi penggunaan madding bermuatan barcode ebook. Madding bermuatan barcode ebook dalam pengabdian ini terdiri atas 24 barcode ebook: 8 barcode tentang novel, 8 barcode tentang materi PIK Remaja dan 8 barcode tentang isu remaja yang populer. Hasilnya, peserta PIK-R telah menyelesaikan rata-rata 14 bacaan yang dimuat dalam barcode ebook yang tersedia di madding. Keberadaan madding bermuatan barcode ebook memiliki peran yang sangat besar dalam menarik dan menumbuhkan minat membaca di kalangan remaja.

\section{Saran}

Kegiatan pengabdian ini memanfaatkan penggunaan barcode ebook. Untuk kegiatan pengabdian berikutnya, dapat membuat aplikasi bahan bacaan android agar lebih fleksibel dan dapat meningkatkan ketertarikan remaja dalam membaca.

\section{DAFTAR PUSTAKA}

Dalman. (2013). Keterampilan Membaca. Jakarta: Raja Grafindo Persada.

Kasiyun, S. (2015). Upaya Menumbuhkan MInat Baca sebagai Sarana untuk Mencerdaskan Bangsa. Jurnal Pena Indonesia. 1 (1). 79-95.

Nursisto. (2005). Membina Majalah Dinding. Yogyakarta: Adicita Karya Nusa. 
Pemanfaatan Mading Bermuatan Barcode Ebook Untuk Meningkatkan Minat Dan Budaya Baca Kelompok Pusat Informasi Konseling Remaja (PIK-R)

Sirojul Munir, Asep Hidayatullah

Sudarsana, U. (2010). Pembinaan Minat Baca. Jakarta: Universitas Terbuka.

Suwarno, W. (2011). Perpustakaan dan Buku: Wacana Penulisan dan Penerbitan. Yogyakarta: Ar-Ruzz Media.

Tarigan, H. G. (2008). Membaca sebagai Suatu Keterampilan Berbahasa. Bandung: Angkasa. 